\title{
On Fairness \& Sustainability: Motivating Change in the Networked Society
}

\author{
Somya Joshi \\ Dept. of Computer and Systems Sciences \\ Stockholm University \\ Borgarfjordsgatan 12 SE-164 07 Kista, Sweden \\ somya@dsv.su.se
}

\begin{abstract}
Caught between the infinite promise unleashed by technology proliferation and the unprecedented scale of resource depletion, waste and inequity, we inhabit a space where critical alternatives are sought more than ever. As a reflection of the above, we find in HCI, a slant towards technological quick-fixes to existing sustainability problems, as opposed to a more holistic approach that includes behavioural and societal change. It is within this context that this paper is situated, where we propose a socioecological approach and argue our case for a life-cycle lens towards building systems that are in line with our current understanding of the earth's finite resources. We do so by presenting an illustrative case study of what such critical alternatives might look like, by examining the Fairphone movement. We contribute to a deeper understanding of how social value laden enterprises along with open technological design can shape sustainable relationships between our environment and us.
\end{abstract}

Keywords-Sustainability, Open Technologies, Critical Alternatives, Transactions, Social-Ecology Introduction (Heading 1)

\section{INTRODUCTION}

How can Information \& Communication Technologies (ICTs) participate and contribute to catalyze societal change? How do we build and design these technologies to sustain movements centered around fairness \& openness? These issues and other central questions have been introduced within the Sustainable HCI (SHCI) literature $[4,17,9,20,13,14,15,12,31,32]$. This pioneering body of research work has drawn on theoretical and applied developments that relate to third wave HCI [6]. By transcending traditional HCI boundaries, this body of work is at once deeply concerned by environmental [1], sociopolitical [12], political economy [18], social sustainability [5] and ecological concerns [26]. Latest developments in SHCI clearly indicate there is today an emergent research community committed to rethinking human computation from visions of the world that are more in line with contemporary moral and environmental conundrums $[3,7,8,2,17,18,19,22,31]$. Our paper follows from the above, focusing primarily on the social value laden enterprise and its processes of activism and co-creation that inform critical alternatives within the SHCI discourse. We do so via the illustrative lens of a case study of Fairphone (a social enterprise working with the design, manufacturing and

\author{
Teresa Cerratto Pargman \\ Dept. of Computer and Systems Sciences \\ Stockholm University \\ Borgarfjordsgatan 12 SE-164 07 Kista, Sweden \\ tessy@dsv.su.se
}

supply of smartphones) that enables us to conceptualize the transformational power of technology within the sustainability context. We start the paper by presenting the core principles of our theoretical framework - the social ecology approach that has informed our analysis of the qualitative data collected (i.e. interview transcripts, expert reports, blog entries, social media excerpts and forum debates). Next we introduce the case study of Fairphone along with the methodology applied. Following from this, we present our research findings, framed as four critical alternatives for the design of sustainable relationships with technology. We then go on to elaborate on these findings in a discussion that offers pragmatic lessons learnt on how social change can be brought about within the entrenched discourse of consumption, growth and technological progress. We conclude summarizing the paper's contribution to a deeper understanding of how social value laden enterprises along with open technological design can shape sustainable relationships between our environment and us.

\section{THEORETICAL UNDERPINNING}

Our interest in the social ecology perspective underscored by Stokols et al. $[16,28]$ is due to its understanding of how the resilience of human-environment systems can be enhanced. Grounded in Husserl's phenomenology (i.e. early work on natural and semiotic worlds), Stokols et al. [28] consider resilience as a qualitative attribute emerging from the mutual relationships between the natural dimension (i.e. the material facet) and the dimension of meaning (i.e. the social-semiotic facet). For Stokols et al. [28] the resilience of human-environment systems depends on the "active or missing, supportive or perverse" [16] relationships between these dimensions and multi-capital formation. Examining these intricate relationships, we believe, is key for envisioning the role of computing in a world with limited natural resources. In order to understand how the social ecology perspective contributes to our field, we elaborate on its four core principles: 


\section{A. Multidimensional structure of human environments and multiple levels of analysis}

This principle encompasses the idea of the multifaceted nature of human activity (i.e. social, cultural) along with an understanding of multiple units of analysis (i.e. groups, households, communities, towns, organizations, societies) that can be focused on when studying human environments. As such, this principle calls for an integrative analysis of sustainability issues in HCI. This provides a context for the understanding of how its natural-ecological and sociosemiotic components affect each other and increase -or decrease- the resilience of such human environments systems. In SHCI, we see illustrations of integrative analysis in studies presented by [13] where they critique current SHCI approaches that compartmentalize sustainability as primarily an environmental problem [9]. Peirce's et al. [21] work on practices is another example of how studies in SHCI can look at design of ICT with a strong consideration of the social, cultural, and material contexts in which those practices are situated. Interest in the analysis of different facets of human-environment systems goes hand in hand with considering different units of analysis in these systems (e.g. individuals, groups, which also comprise communities, organisations, social movements and larger populations). As such the quasi-exclusive focus on individuals (i.e. users) that has so far characterized the work conducted in SCHI [9] is challenged by this principle that takes account of multiple units of analysis that can be included in the examination of social movements. In that respect, work conducted by $[1,13,32]$ point to this direction through for example questions of scale [12]. Ultimately, the principle about the multiple levels of analysis that are intertwined with issues pertaining to the environment, can also be grasped in terms of analyzing a "conjoint phenomena at different scales approaching environmental settings in terms of their physical and social components, natural or built - designedfeatures, material and semiotic qualities, and their scale of immediacy to individuals and groups, organizations, communities or populations" [28. p.2]. Change in the multidimensional structure of our human systems operates in relation to each other, making its physical-material (observable) and social-semiotic (perceived) components co-evolve. We find the idea of co-evolution of naturalecological and social-semiotic dimensions of interest to our field as it makes clear that our attempts to act and/or think about sustainability issues can not be regarded as simply a matter of taking the environment into account. It goes much deeper than that as the crux of the question lies in comprehending that we are our environment and that human behavior "is a co-evolutionary part of the web of life" [23 p.562].

\section{B. Context}

According to [16] "The interaction between multiple dimensions of human activity is most deeply analyzed and understood in context" [16 p.2]. Thorough analyses of local contexts contemplating multiple dimensions lead us to the realisation that "local settings and organizations are nested within more complex and remote regions" [16 p3.]. As such, attempts to discern and build up the resilience of particular human-environment systems needs to account for the interdependencies existing among immediate and more distant environments [30]. Immersed in local, specific contexts, researchers, designers, innovators, and activists are better grounded and equipped to figure out which potential changes, production and processes can be triggered in relation to the sustainability of our interrelated human systems. Of special interest to us here, is the context of contemporary social innovation movements that are striving toward alternatives.

\section{Transactions}

"Social ecology, draws upon key concepts and assumptions from systems theory (e.g. interdependence, feedback, homeostasis) for the understanding of the interrelationships between social and physical systems and attaches great importance to describing how changes in one dimension are related to changes in another" [28,p.3]. These continuous, bidirectional and mutually influencing relationships between the material-ecological (i.e. natural) and social-semiotic dimensions (i.e. meanings, values, moral judgments), lead to changes in our human-environment systems that are neither transformations nor translations but transactions. Transactions in the sense that they are not fungible as changes in one dimension (i.e. meanings, moral judgments) bring changes in another dimension (i.e. technology, environment). More specifically, changes in the social ecology approach are grasped in terms of forms of capital [28] they mobilize (i.e. natural, technological, man-made buildings, social, human and moral capital) in a given human-environment system. Resilience emerges thus "through effective mobilization or capitalization of these community assets [29]". In SHCI, the concept of transactions provides us with a terminology to talk about qualitative changes among multiple relationships that enhance or not (i.e. depending of the degree of adaptability and type of resources, assets or actors exchanged) the resilience of our human-environment system. Work conducted by Remy and Huang [24] on the issue of obsolescence resonates with the concept of transactions, as their work points to the rapid pace of technological development and the resulting replacement of end-user devices that have unleashed an unprecedented surge of electronic waste upon our society. In the same vein, Blevis et al. [4] refer to the notion of "new luxury" and underscores luxury and material success as obstacles in tackling obsolescence since some consumers-commonly referred to as early adopters - always like to have the most novel technology. New luxury, according to [4] might be leveraged to turn this traditional notion of material success and luxury against itself to promote a more sustainable behavior. This can be done, for example, by shifting the societal paradigms such that owning a device for a longer 
amount of time becomes more desirable than buying a new one. These examples illustrate developments issued from a systemic thinking linked to notions of re-use, common ownership, transferability, augmentation, and longevity which are key obstacles that design can offer to fight obsolescence. The concept of transaction has implications for SHCI in terms of how we think about the delineation and understanding of its design space. We see it as an arena for spelling out how ICT can instrument transactions between actors, assets and resources that can contribute to enhance the resilience of human-environments systems.

\section{Trans-disciplinary Action Research}

"Social-ecological analysis of human-environment systems emphasizes a transdisciplinary action research orientation in which diverse knowledge cultures or epistemologies are brought together for the improvement of the resilience and sustainability of people-environment systems" [28,p.3]. We understand this principle as an invitation to expand SHCI borders and engage in a broader conversation with other disciplines. For instance perspectives from, Ecological Economy [16], Political Ecology [23], Environmental justice and governance [12], have traditionally elaborated on the relationships between ecology, economy and politics; relationships that are key for rethinking our technologies for "the age of consequences" [27]. By introducing a transdisciplinary action research orientation into SCHI, we inadvertently open doors to other actors such as community activists, ecologists, politicians, policy makers, non-profits organizations and citizens also concerned by environmental and sustainability issues. These actors together with designers and researchers could eventually envision sustainable techno-cultural practices for resilient humanenvironment systems.

\section{FROM THEORY TO PRAXIS: THE FAIRPHONE ROADMAP}

Emerging from the above theoretical discussion, we set out to examine what such an alternative might look like in practice. Within the remit of this paper we look at the illustrative case study of Fairphone [11]. Fairphone started off as an awareness raising campaign in 2010, mainly focused in the first instance on conflict minerals within the context of the smartphone industry. In the absence of a real alternative to point to, Fairphone emerged as a social enterprise in 2013, as the outcome of a crowd-funded campaign, designed to produce a truly 'fair' phone.

The four main action points that Fairphone has built itself around are: mining, manufacturing, design and life-cycle. We chose this case as it provided us a window into two worlds simultaneously: that of a social enterprise setting out to engineer and sustain a movement (based on changing relationships and practices within the domain of technology design and consumption); and that of a technical artifact designed to embody the life-cycle approach - built on the "fairware" principles (open hardware and software, conflict free and fair in terms of workers rights, circular economy - from "cradle to cradle" approach). The four core principles that enabled us to frame our research problem within this paper were the following:

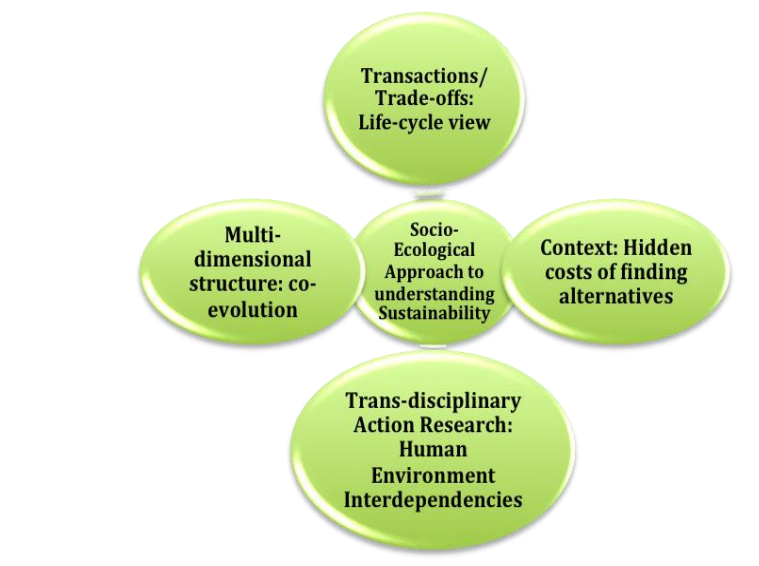

Figure 1: Social-Ecology Approach to understanding Sustainability

\section{Empirical Design}

This paper draws on data collected at two levels. Primary: comprising of semi-structured interviews conducted iteratively, with impact development and product strategy staff at Fairphone. Secondary: data collected via the website, blogs and online documentation, as well as the critical voices emerging from the wider community of users and supporters. The latter consists of early adopters, experts, users, designers and partner organisations. We also draw on social media data from Twitter (\#wearefairphone) and Facebook. To get a glimpse of the network within which Fairphone is situated, we refer to Fig. 2 to highlight their reach on popular social media sights such as Facebook. In addition to this, the organization has 15,700 followers on Twitter, 43,632 subscribers to the Fairphone and in 2014 alone the Fairphone website was visited 2,365,732 times, from 196 countries.

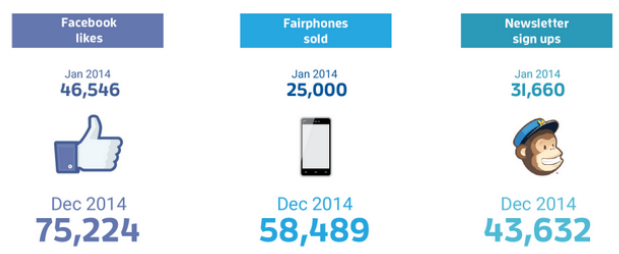

Fig. 2: Fairphone in the Networked Society

The analysis of the data was conducted using a procedure known as explication de texte, or close reading, an analytical method that originated in the humanities [25]. We took into consideration texts (i.e. interview transcripts, expert reports, blog entries, social media excerpts and forum debates), from which we arrived at conceptual threads. They constitute the findings of our study, which we will unpack in the following section. 


\section{FINDINGS: CRITICAL ALTERNATIVES FOR SUSTAINABILITY}

From the data analyzed four themes emerged that embody what we analyze as critical alternatives for the design of a sustainable relationship with technology. These alternatives are further elaborated in the discussion section of this paper, when we look at them through the lens of the social ecology perspective.

\section{A. Situating Fairness within a Circular Economy:}

Design alternatives on the one hand are based on the principle that change arises when technologies provide opportunities for individuals to live differently [32,14]. Sustainability in this context is a byproduct of the artifact itself. On the other hand, design choices can be seen to be framing change by providing opportunities for community debate [10], in which the direction for change is set by communities themselves and not the technological artifact per se. The key rationale for us to select Fairphone as our case context, comes from both these drivers for change being manifest within its narrative. Below, in an annotated version of their own manifesto, we highlight the language and metaphors that the organization employs to imagine itself. In their own words they conceptualise their product as a "storytelling device" - one that engages in a narrative exercise to challenge existing relationships in consumption of technologies. By prioritizing "social values", the organization at the outset hopes to delineate itself from others that compromise degrees of independence (in funding) by allowing economic discourses to shape their agenda.

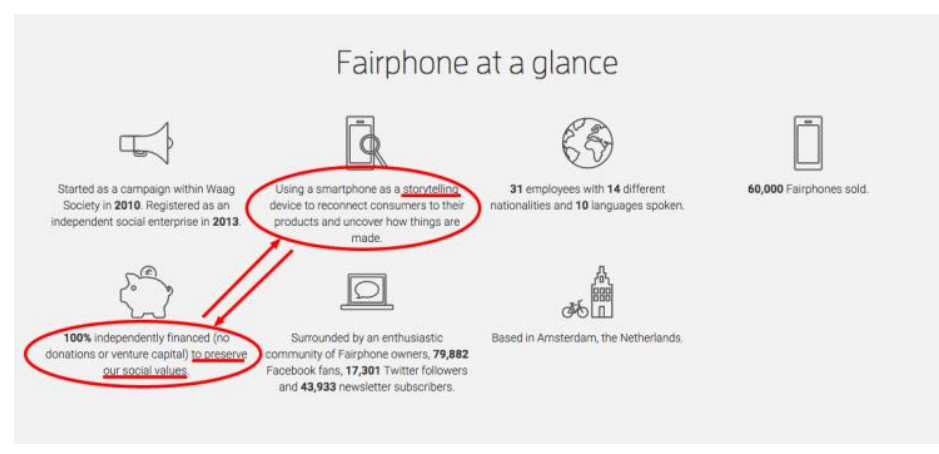

Figure 3: The narrative of Fairphone

When talking about the perceived impacts of Fairphone, the team visualized these as: "...uncover(ing) complex systems to change how things are made. By creating a smartphone, we're opening up the supply chain, building new relationships between people and their products and starting conversations about what is truly fair." Again, what we see here is the focus on 'starting conversations' rather than building artifacts or complete solutions. Defining themselves as a social enterprise then, the organisation has opted for a mandate that is more rooted in ethics of sustainability than in any desire to be industry leaders in the smartphone domain. One employee in charge of product design, articulated his dream of Fairphone in the future being a successful analogy of a Not-For-Profit Organisation, in terms of its contribution to socio-environmental matters. This translates into a set of compromises or trade-offs, where by visualizing themselves as a movement rather than as a corporate entity per se, the group is unable to diversify its product range or maximize much needed profits in order to grow, but instead keep a steady focus on the goal at hand which is to promote notions of fairness and quality control of the existing artifact (a fair smartphone). What is of particular interest here, is that the organization speak of a circular economy centered around the ideas of reparability, reuse, remanufacturing and recycling of components - in other words an economy of artifacts and tangential environmental impacts, rather than an economy based on financial markets and profits alone.

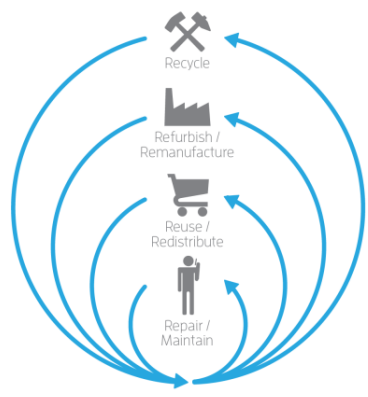

Figure 4: Circular Economy of Fairphone

\section{B. Co-evolution and Changing Relationships:}

Just as DNA comes in pairs, we were informed in our discussion with the Head of Impact at Fairphone, "...the DNA of this social enterprise consists of two strands: on the one hand it aims to change the relationship between users and how they consume technology, on the other hand it aims to use technology as an innovative tool to alleviate societal problems that emerge from its supply chain". In the case of the latter, this goes a long way to bridge the gap between the potential opportunities offered by technology and the unsustainability it leaves in its wake. In the case of the former strand, the relationship is influenced by increases in transparency, feedback, participation and co-creation of both a technical artifact and a social movement.

One member of the team, working on product design, commented that it was not just the consumer, with whom the relationship was transforming, but also with industrial traders (such as for example telecom providers and plastic suppliers) who were coming to view Fairphone as an experiment they increasingly sympathized with. It provided them proof that an alternative could exist.

The above links well to the idea of co-evolution, where the physical limitations of the environment and the sociosemiotic tensions arising from ever increasing demand, result in a strong need for technology design choices to go hand in hand with social values. Interestingly, one of our 
respondents while talking about the physical artifact of the smart phone, mentioned the following limitation when he said: "Within a limited frame of so little space, there is so much technology and so much complexity - everything interacts with everything." Although he was referring to the hardware environment of the phone, the same applies to a wider socio-ecological frame, we argue, where the interdependencies of resources plays a critical role.

With regard to working within a limited frame of reference, Fairphone has been critiqued by its wider community (social media, blogs, user groups) for having its choice of production factory being in China, where the understanding of worker rights within the context of 'fairness' is far removed from the definitions accepted in Europe. They have been questioned on why they did not opt for a European production base or select a partner in China where worker unions were formalized and in place to protect as well as ensure fair working conditions. In response Fairphone has argued that the mandate of the group was to "change a system from within" and to create a contextualized voice for questioning the hidden costs of our everyday consumption choices that was hitherto silent. During our interview we were explicitly informed: "...it would go against the model of Fairphone, to avoid the context of the problem. The model is very much about intervening and engaging with the context to change it." What we learnt from this discussion was that only by facilitating dialogue and subsequent change in relationships (between an intricate web of workers, consumers, governments and citizens) within regions in Asia and Africa where the supply chain was embedded, could real long-term impacts be achieved. Avoiding direct engagement with such socio-environmental and technological systems, would mean skirting around the issue, with no real change. However, it should be mentioned that two key challenges stand in the way of realizing this goal of changing relationships between users and their technology quick-fixes. That of scalability, and the slow pace of change within the sustainability context. With regard to the former, a small outfit such as Fairphone (30 fulltime staff in Amsterdam) simply (to put it in their own words) "can not afford to move the entire supply chain of production from China to Europe." This alludes to a set of compromises that shift their roadmap and milestones to impacts more graspable, small scale and localized in the early stages of development. With regard to the latter challenge, in an industry and market such as that of smart phones and more broadly consumer electronics, the rate of change in product development feeds into an expectation of heightened novelty seeking. Within this environment, to engage in a slow deliberate march towards the attainment of sustainability goals, most of which are not immediately apparent (changing worker relationships, acceptance of standards and regulation with regard to conflict free mining, recycle-reuse impacts), often translates into frustration and impatience on the side of the end user community. This further relates to management of expectations when venturing to provide critical alternatives within an arena of entrenched discourse.

\section{Tools to be Curious with and Tools for Sustainability:}

With regard to the actual technical artifact at hand, Fairphone has positioned itself along a roadmap towards 'Fairware', which is a concept expressed in both long and short term ideas. Thinking short term, Fairphone aims at being open source to allow lead users to optimize it, as well as modular so others can repair/replace parts to use the phone longer. In the long term, "Cradle2Cradle" design would enable reuse scenarios, where old modules could be used to upgrade other devices, which would allow circulating across product cycles. This would considerably cut down on waste and forced obsolescence in the long term. As one participant, of a design bootcamp that was set up to develop the next generation of Fairphones, said: "It's a phone that is developed by the community who all want to work toward improving the status quo by combining their abilities." The trade offs of opening up both the technical design of the phone and the future evolution of it as a social enterprise, to the wider user community, are manifold. Sustainability in hardware choices translates into decisions such as the modularity of the phone, its openness to friendly hacks and the conflict free nature of materials used, which all make costly demands on resources, that are otherwise spent on user experience (e.g. larger screens, lighter phones, cheaper and faster processors, better cameras etc.) By committing itself to a life-cycle approach where all aspects from sourcing minerals to end of life recycling and reuse options are factored in, and making "reparability" a central tenet of Fairphone 2, the organisation has opted into a tradeoff (where the logic of profit and market share is compromised as a result of the hidden costs that accompany the logic of fairness). This is a critical alternative where instead of operating in a straight line determined by supply and demand, the aim is to achieve a seamless, renewable flow from creation to use and back again. Products are designed for multiple loops of repair, reuse, remanufacturing and recycling to extend their lifespan and eliminate dependence on raw materials. One of the founding members of the Fairphone team gave us a clear example of this tension and trade-off: "We are trying to avoid using coatings for the plastic casing of the phone, as they are detrimental to the health of the workers as well as harmful for the environment. However plastics without coating of some sort look very ugly and so this is something we are experimenting with to innovatively come up with a solution. It is hard to say which way the tradeoff will go. Perhaps in the end we will go with the coating, perhaps we will hold our ground and find an alternative. In either case, by trial and error and taking small steps at a time, we proceed as a learning organization." Thus inherent in the decision to go with a better looking artifact or a less environmentally harmful one, or the decision between chipsets (hardware) that would allow open source software possibilities - lies a 
transaction built upon the social values of the organization. During our interviews with the team, we were provided with the following view on the evolution of the artifact as well as the movement: "Today Fairphone is not for everyone. The early adopters or aware consumers are the ones who are part of the community, because either they are interested in conflict minerals, or workers rights, or environmental impact. However by joining the movement, they gain a context to this awareness and see the bigger-linked picture of the life cycle approach we adopt. We are essentially providing them with the tools to be curious with." The cocreation then takes place not just at the level of the product design, but also in terms of education and capacity building on the part of the wider Fairphone community.

\section{Transformative Road of ICT - Process to Product:}

By adopting a multidimensional view of how change can be engineered both within the artifact and the social domain, we discovered that Transparency served as a key tenet of the movement. For instance by making openly accessible all independent assessment reports and audits on working conditions, fairness of minerals sourced and the design decisions emerging from bootcamps, Fairphone is in a sense making itself more vulnerable to criticisms that reflect the slow pace of change or impacts being felt. In its acknowledgement of its mistakes, and the compromises that dot the path towards arriving at any tangible understanding of fairness, the movement has managed to hold onto the credibility of its core objectives. A member of the team, working with innovation and outreach mentioned to us: "There are those that would wait till everything was perfect. However, I personally don't believe in 100\% Fairness. We are always in 'Beta' here at Fairphone, we make mistakes, we learn. And in being transparent about the process, we hope we inspire real change." Thus the biggest impacts (at least with regard to the first iteration of the phone and organisation's development) were being felt in the discussions, debates and choices that were emerging within a landscape that had been conspicuously silent so far on matters of fairness, ethics and sustainability. This was enshrined in the belief of the impact development team, " $B y$ making the process more fair, we are hopefully making the product more fair." But one can argue, that this is still the world-view and perspective of Fairphone itself. Where do the user community and the balance of opinions come in? On closer examination of the forums and social media sphere, where the wider community of Fairphone users and supporters debated candidly what they found inspiring as well as disappointing, we found intriguing evidence of a demanding and critical audience. One early adopter expressed his concern about the gap between rhetoric and reality: "You have already published the sources of the materials and explained why you have chosen each source. So I know that my mobile phone doesn't support conflicts. But you haven't told us much about the situation of the workers who produce the Fairphone. I know that it's really difficult to check all your partners but I'm not able to trust "pure words". You talk about transparency being a crucial part of your "journey". Everybody can describe goals but this is what other companies (can) do. Proof and data are really important, too, not just "newspaper announcements". I want to support you but on the other hand I don't want to have any doubts left when I use my phone." Thus what we find here is an example of the community network within which Fairphone as a movement emerges. Here is a community that is critical and demands more than placatory rhetoric or greenwashing with regard to sustainability. In response, Fairphone chose to adopt an independent, third-party social assessment organization to perform an assessment of their production factory in China. An interesting expression from the part of the independent social assessment organization ${ }^{1}$, regarding their mandate, was: "We want also to balance the values of global business with the principles underlying social compliance, to measure the international perspectives on social compliance against the practices of the local culture and to weigh the individual conditions at the factory in regard to the necessarily high standards set by the international brand. " Once again we find the call for balance and contextualization when speaking of compliance to certain social values that envelop the wider supply chain. By creating avenues for such dialogues between concerned consumers and independent technology as well as social assessment initiatives, what is at stake here is a transformative process that yields critical alternatives to an otherwise rigid duality of supply and demand.

\section{DISCUSSION}

Drawing on these critical alternatives for sustainable relationships with technology, we elaborate on some practical lessons learnt on how change can be brought about within the entrenched discourse of consumption, growth and technological progress. We do so by drawing upon a set of metaphors, that emerged from the empirical case context and can be explained from the perspective of social ecology $[28,16]$

1. Opening up the 'black box' of design metaphor: One startling difference we found between the model adopted by Fairphone and other more mainstream consumer electronics manufacturers, concerns the openness in design and the holistic life-cycle view. Be it manifest in the urban mining workshops organized routinely or the e-waste reduction efforts in Ghana, the clear message emerging from such initiatives is centered around the concept of sustainability. Urban mining emerges as one critical alternative from within this context, as a way to change the existing imbalance, by the extraction of minerals from existing products. Fairphone actively encouraged its users to look behind the screen of their mobile phone, and discover that

${ }_{1}$ http://www.fairphone.com/wp-content/uploads/2013/12/Fairphone-Madewith-Care-Social-Assessment-Program.pdf 
there lie over 30 different non-renewable minerals ${ }^{2}$ within. Whether a car a laptop or a toaster, cities are filled to the brim with electrical devices that would render most urban landscapes as modern mine sites. The idea was that once users have unscrewed the back cover of their technological artifact (in this case a smart phone), and identified the components, the urban mining workshop would aim to unravel some of the phone's hidden stories. From pollution and extremely dangerous working conditions to child labor, we learn that a number of mining-related practices desperately require improvement. One option would be to go for hiding this inconvenient body of knowledge behind sealed, glued and proprietary locked in devices, where the design serves as an impenetrable casing which keeps all unpalatable, guilt-inspiring footprints of our consumption behaviours, neatly out of sight. The other option would be to open the design, processes, supply chain and impacts, to truly open a space for innovation, wherein sustainability can feature as a core tenet rather than as an afterthought. What initiatives such as Fairphone are essentially engaging with is a step towards societal change via the provision of tools to be curious with (as opposed to a more paternalistic, top down education model for users).

From the DR Congo, to China, to Europe and places in between, one can trace the international journey made by components, thereby uncovering the complexity of the supply chain, opening up a dialogue on our role as consumers. Such an interest in sharing critical knowledge about what a technology artifact consists of and how its components relate to the environment, we argue, mobilizes human capital [28]. This is essentially "capital that is created through changes in persons (e.g. educational experiences) equipping them with new skills and capabilities that enable them to act in new ways" [28 p. 4]. Mobilization of human capital can be understood as a response aiming to adapt to the issue of obsolescence [24] of electronic devices through a way (i.e. urban mining) that intends to increment the resilience of our environment.

2. This brings us to the second metaphor of "getting one's hands dirty". Here we refer to the model of engagement and direct intervention with diverse societal contexts for change. Affecting change in the highly varied and sensitive social contexts of Africa and Asia is one pragmatic step, in our opinion, towards building up resilience of particular humanenvironment systems. In particular the need to account for the interdependencies existing among immediate and more distant environments [30] is what is at play here. More specifically the interest in engineering social change through action in-situ (e.g. visiting tin, tantalum and tungsten mines in DR of Congo and Rwanda) brings the Fairphone organisation in closer contact with the local meanings embedded in the route minerals take from mine to

2

http://www.basel.int/Implementation/TechnicalAssistance/Partnerships/MP PI/MPPIGuidanceDocument/tabid/3250/Default.aspx component (e.g. meeting the stakeholders involved in the extraction of minerals and become aware of the challenges they are confronting). In this sense, direct relationship with the context facilitates the realization of dimension of meaning that is at play vis-à-vis mining and conflict minerals within the domain of ICT production and use.

3. Creating 'value' in resilience - Following from the point above, we find another interesting insight to carry forward from our empirical case, that connects with mobilization of moral capital (e.g. "embracing ethical norms to guide the development and distribution of limited resources among people" [30,p.4]). We look at the value being generated here via technological design and interaction. More particularly, in the case of Fairphone, the value per se was linked intrinsically to the environmental footprint, repairability, and social sustainability, as opposed to a notion of value linked to the artifact's appearance, financial cost, or status. By adopting a life-cycle view, and interlinking design as well as consumption decisions made closer to home, with impacts in far away and often disconnected places, the very discourse of innovation and sustainability was reexamined and reworked. In terms of transactions, to be able to affect behavioural and societal change, a key lesson to be learnt is that we need to generate and design for value into our everyday practices as well as in our relationships with technology.

4. Incremental change vs. paralysis of perfection - When starting out on any journey, especially one as daunting as challenging unsustainable practices within the domain of consumer electronics, an argument often used as deterrence, is that the playing field is less than perfect. In other words the expectations of addressing all the complexity of a problem and attaining some notion of absolute sustainability or absolute fairness, is high. In the case of Fairphone, we were told on more than one occasion, that the initiative didn't believe in $100 \%$ fairness. Instead they saw themselves as a learning organization, which through a process of trial and error achieved incremental change within the entrenched discourse of profits and technology driven consumption.

5. "Everything interacts with everything" - this relates to the life cycle and socio-ecological frame within which Fairphone is operating. In this final metaphor, we look at the notion of interconnections and interdependencies. By adopting both a multi-dimensional approach within our research methodology as well as in our understanding of the thematic of sustainability, what we argue for is a nonreductionist perspective. In other words, we argue against solutions for socio-environmental problems via technology quick-fixes. Instead we make the case for a more systems science approach, where be it a technical artifact, with myriad components interacting in infinitely complex ways, or a social system such as a movement, with diverse actors, drivers and game-changers, the gains, losses, feedback, 
rebounds and interchangeability of transactions are all taken account for. It is only by interlinking these threads, can some real headway be made in changing established behavioural patterns that have an impact on sustainability.

\section{CONCLUSION}

Through the course of our research we found Fairphone to be an organisation in its early stages of evolution, experiencing the teething pains expected of any initiative aiming to challenge the status quo. Seen from the lens of the socioecological perspective, we perceived it to be a step towards opening the discourse of critical alternatives within sustainable HCI. In this paper, we have presented critical alternatives, both at the theoretical level (with the socioecological approach as a lens) and at an applied level (via the illustrative lens of the Fairphone case). We have argued that it is counter-productive to consider broader concepts of sustainability and fairness in their absolute sense, which require a perfect playing field for any critical alternatives to exist. Instead, an incremental or gradient approach, which adopts a learning model, is more resilient, as demonstrated by our case. In this paper we have offered critical insights and pragmatic lessons learnt on how change can be brought about within the entrenched discourse of consumption, growth and technological progress. In doing so we have contributed to a more holistic understanding of how social value laden enterprises along with open technological design can shape sustainable relationships between our environment and us.

\section{REFERENCES}

[1] Aoki, P.M.; Honicky, R.J.; Mainwaring, A.; Myers, C.; Paulos, E.; Subramanian, S. and Woodruff, A. A Vehicle for Research: Using Street Sweepers to Explore the Landscape of Environmental Community Action. In Proc. CHI'09 ACM (2009), 375-384.

[2] Baumer, E and Silberman, S. (Baumer, E.P.S. and Silberman, S.M. When the implication is not to design (technology), In Proc. CHI EA'11. ACM (2011), 2271-2274.

[3] Bellotti, V., Caroll, J.M. and Kyungsik, H. Random acts of kindness: The intelligent and context-aware future of reciprocal altruism and community collaboration. In Proc. of CTS. IEEE (2013), 1-12.

[4] Blevis, E., Makice, K., Odom, W., Roedl, D., Beck, C., Blevis, S., Ashok, A.: Luxury \& new luxury, quality \& equality. In Proc. DPPI '07, ACM Press (2007), 296-311.

[5] Busse, D.; Blevis, E., Beckwith, R.; Bardzell, S.; Sengers, P.; Tomlinson, B.; Nathan, B. Social Sustainability: An HCI Agenda. In Proc. CHI EA'12. ACM Press (2010), 1151-1154.

[6] Bödker, S. When second wave HCI meets third wave challenges. In Proc. NordiCHI 2006, ACM Press (2006), 1-8.

[7] Cerratto Pargman, T. A European strand of Sustainable HCI? Position Paper presented at NordiCHI 2014. http://tessy.blogs.dsv.su.se/publications/2014-2/

[8] Cerratto-Pargman, T. and Joshi, S. Understanding Limits from a social ecology perpsective. LIMITS 2015. http://www.limits2015.org

[9] DiSalvo, C., Sengers, P., and Brynjarsdòttir. Mapping the landscape of sustainable HCI, In Proc. CHI'10. ACM (2010), 1975-1984.

[10] DiSalvo, C. Adversarial design. MIT Press, 2012; Hirsch, T. Water wars: designing a civic game about water scarcity. Proc. DIS '10. ACM (2010), 340-343.

[11] Fairphone. www.fairphone.com
[12] Dourish, P. HCI and Environmental Sustainability: The Politics of Design and the Design of Politics. In Proc. DIS'10, ACM Press (2010), $1-10$

[13] Håkansson, M. and Sengers, P. Beyond Being Green: Simply Living Families and ICT. In Proc. CHI'13. ACM (2013). 2725-2734.

[14] Håkansson, M. and Sengers, P. No easy Compromises. Sustainability and the Dynamics of Change. Proc. Of DIS (2014). ACM Press. 1025-1034.

[15] Joshi, S. and Cerratto-Pargman. T. In Search of Fairness. Critical Design Alternatives for Sustainability. In Proc. Of Critical Computing 2015. ACM Press (2015).

[16] Lejano, R. and Stokols, D. Social Ecology, Sustainability and Economics. Ecological Economics, 89 (2013), 1-6.

[17] Nardi, B. The Role of Human Computation in Sustainability, or, Social Progress is Made of Fossil Fuels. In Handbook of Human Computation, New York, Springer, 2013.

[18] Nardi, B. Inequalities and Limits. LIMTS 2015. http://www.limits2015.org

[19] Pargman, D. On the Limits of Limits. LIMITS 2015. http://www.limits2015.org

[20] Pargman, D. and Raghavan, B. Rethinking sustainability in computing: from buzzword to non-negotiable limits. In Proc. NordiCHI'14. ACM Press (2014), 638-647.

[21] Pierce, J., Strengers, Y., Sengers, P. and Bödker, S. Introduction to the Special issue on Practice-oriented approaches to sustainable HCI. ACM TOCHI. Volume 20, Issue 4. 2013.

[22] Pierce, J. Undesigning Technology. In Proc. CHI'12. ACM Press (2012), 957-966.

[23] Pezzoli, K. Sustainable development: A transdisciplinary overview of the literature. Journal of Environmental Planning and Management, 40:5 1997, 549-574.

[24] Remy, C. and Huang, E. Addressing the Obsolescence of end-user devices: Approaches from the field of Sustainable HCI. ICT Innovations for Sustainability. Vol. 310. Springer 2015, 257-267.

[25] Richards, I.A. (1930). Practical Criticism. A study of Literary Judgment. Kegan Paul \& Co.Ltd. London.

[26] Silberman, S. and Tomlinson, B. Toward an Ecological Sensibility. In Proc.CHI'10 EA. ACM Press (2010), 3469-3474.

[27] Silberman, S. Information Systems for the age of consequences. LIMITS 2015. http://www.limits2015.org

[28] Stokols, D., Lejano, R. and Hipp, J. Enhancing the Resilience of Human-Environment Systems: a Social Ecological Perspective. Ecology and Society, 18(1), 7.(2013), 1-12. http://dx.doi.org/10.5751/ES-05301-180107

[29] Stokols, D., J. G. Grzywacz, S. McMahan, and K. Phillips. Increasing the health promotive capacity of human environments. American Journal of Health Promotion (2003). 18:4- 13. http://dx.doi.org/10.4278/0890-1171-18.1.4

[30] Stokols, D., S. Misra, M. G. Runnerstrom, and J. A. Hipp. 2009 Psychology in an age of ecological crisis: from personal angst to collective action. American Psychologist (2009). 64:181-193. http://dx.doi.org/10.1037/a0014717

[31] Tomlinson, B. Silberman, S. Patterson, D. Pan, Y. Blevis.E. Collapse Informatics: Augmenting the Sustainability \& ICT4D Discourse in HCI. In Proc. Of CHI 2012. ACM Press. 655-664.

[32] Woodruff, A., Hasbrouck, J., and Augustin, S. A bright green perspective on sustainable choices. Proc. CHI’08. ACM (2008),313322 
